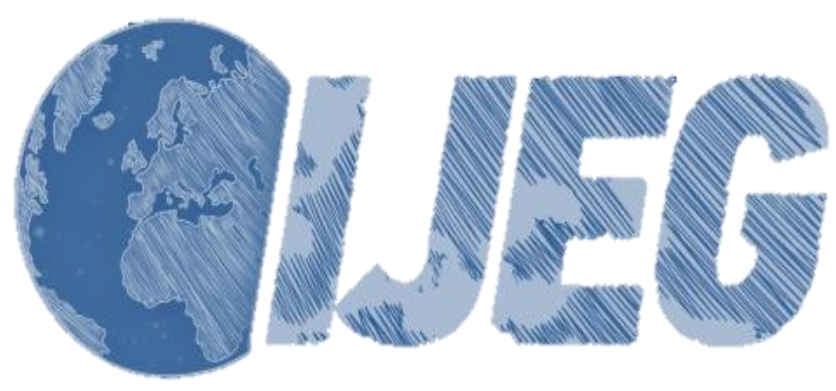

International Journal of Engineering and Geosciences (IJEG), Vol; 5, Issue; 1, pp. 033-041, February, 2020, ISSN 2548-0960, Turkey, DOI: 10.26833 ijeg. 580510

\title{
INVESTIGATION OF BLACK SEA MEAN SEA LEVEL VARIABILITY BY SINGULAR SPECTRUM ANALYSIS
}

\author{
Cansu Beşel $^{1 *}$, Emine Tanır Kayıkçı ${ }^{1}$
}

${ }^{1}$ Karadeniz Technical University, Engineering Faculty, Department of Geomatic Engineering, Trabzon, Turkey (cansubesel/etanir@ktu.edu.tr); ORCID 0000-0003-3434-6483, ORCID 0000-0001-8259-5543

*Corresponding Author, Received: 21/06/2019, Accepted: 22/07/2019

\begin{abstract}
The mean sea level has been continuously increasing since the end of the 19th century and will continue to increase in the 21st century. The Intergovernmental Panel on Climate Change (IPCC) states that the sea level will rise by 40-60 cm until 2100. This situation will lead to social and economic problems, especially in coastal areas. For this reason, studies on sea level determination have great importance in our country. In this paper, we used the singular spectrum analysis (SSA) to investigate mean sea level variability along the coasts of the Black Sea, which is an intercontinental inland sea. This study aimed to determine the trend in sea level change along the coasts of the Black Sea over time. The mean sea level data from 10 tide gauge stations (Amasra, Batumi, Bourgas, Constantza, Igneada, Poti, Sevastapol, Trabzon II, Tuapse and Varna) are analyzed in this study. The mean sea level data were obtained from the Permanent Service for Mean Sea Level (PSMSL). SSA was applied to the mean sea level observations at tide gauges stations, and the results were interpreted. According to the analysis results, there are increasing trends at the Batumi, Poti, Tuapse, Constantza, Sevastopol and Varna stations. The obtained trend of Bourgas station is not significant. There is The results of the Amasra, Igneada and Trabzon II tide gauge stations were inadequate in interpreting any change. There were no trends at these stations. Close eigenvalues were computed from the mean sea level at the tide gauge stations. This situation shows that there is a dominant seasonal component in the time series.
\end{abstract}

Keywords: Black Sea, Mean Sea Level, Tide Gauge, Singular Spectrum Analysis 


\section{INTRODUCTION}

The climate depends on the correlation between the atmosphere, hydrosphere, cryosphere and geosphere (Nacef et al.,2016). Sea level rise, which is predicted to significantly affect coastal areas, is one of the most important pieces of evidence for climate change. Identifying and understanding the causes of sea level change are important in climate change studies at global and regional scales. Sea-level change occurs at different rates over a broad time scale depending on the location. Global mean rate which is estimated satellite altimetrybased has reported a $\pm 3 \mathrm{~mm} /$ year change over a few decades (Cazenave et al., 2014). However, this rate varies across the Earth. For this reason, it is important to predict sea level changes, determine the areas that will be affected by these changes and take precautions. Observations of sea level change are also important for geodesy. In geodesy, the determination of sea level change is crucial in terms of identifying the vertical datum and determining the geoid. In the most applications require a datum for determining ocean depths (Yilmaz et al.,2016).

In our country, which is surrounded by the sea on three sides, sea level monitoring and forecasting studies are extremely important. Karaca and Ünal (2003) noted that the sea level increase would cause a loss in our country's national income of approximately $10 \%$.

The estimates of sea level change are computed by satellite altimetry and tide gauge data. Related to sea level, established sea level monitoring networks and data centers have been established at global, regional and local scales. A few of these institutions include the Permanent Service for Mean Sea Level (PSMSL) and the European Global Ocean Observing System (EuroGOOS). The PSMSL serves to provide hundreds of tide gauge data points at monthly and yearly scales, controlling and presenting. In our country, tide gauge data are presented by the Turkish Sea Level Monitoring System (TUDES; URL 1).

Time series models are widely used in the analysis and estimation of climate data. Singular spectrum analysis (SSA) is a powerful technique in time series analysis. This technique is applied to many problems (see,
Ghil et al.,2002). It is particularly advantageous in complex seasonal component estimation and the analysis of non-stationary time series (Hassani et al., 2009). In the literature, there are many studies on SSA theory and applications (Golyandina 2001; Hassani et al., 2009; Golyandina 2010; Golyandina ve Zhigljavsky 2013).

In this study, the mean sea level data from 10 tide gauge stations (Amasra, Batumi, Bourgas, Constantza, Igneada, Poti, Sevastapol, Trabzon II, Tuapse and Varna) were analyzed using SSA. With SSA, the change in sea level along the coasts of the Black Sea, as well as harmonic oscillations at these stations and seasonal effects, will be determined. Concurrently, the sea level change along the coasts of the Black Sea will be interpreted through the obtained results.

\section{DATA AND METHODS}

\subsection{Study Area and Tide Gauge Data}

In this paper, we used the mean sea level data from tide gauge records along the Black Sea coast. The Black Sea is a unique location, as it is the most isolated inland sea in the Atlantic Ocean system (Goriacikin and Ivanov 2006). There are several studies on sea level change in this region. In these studies, the sea level of the Black Sea coast increased rapidly, see Kubryakov and Stanichyni 2013; Vigo et al., 2005; Avşar et al., 2015.

The mean sea level data from 10 tide gauge stations (Amasra, Batumi, Bourgas, Constantza, Igneada, Poti, Sevastapol, Trabzon II, Tuapse and Varna) located along the coasts of the Black Sea are used in this study. The Amasra, Igneada and Trabzon II tide gauges are in Turkey; the Batumi and Poti stations are in Georgia; the Bourgas and Varna stations are in Bulgaria; the Constantza station is in Romania; and the Sevastopol station is in the Ukraine (Figure 1).

We used monthly mean sea level time series from the PSMSL, and the data sets are from the Revised Local Reference (RLR) in the PSMSL (URL 2). The data spans for each station are different from each other, and the data have gaps of $5 \%$ and $14 \%$ (Table 1).

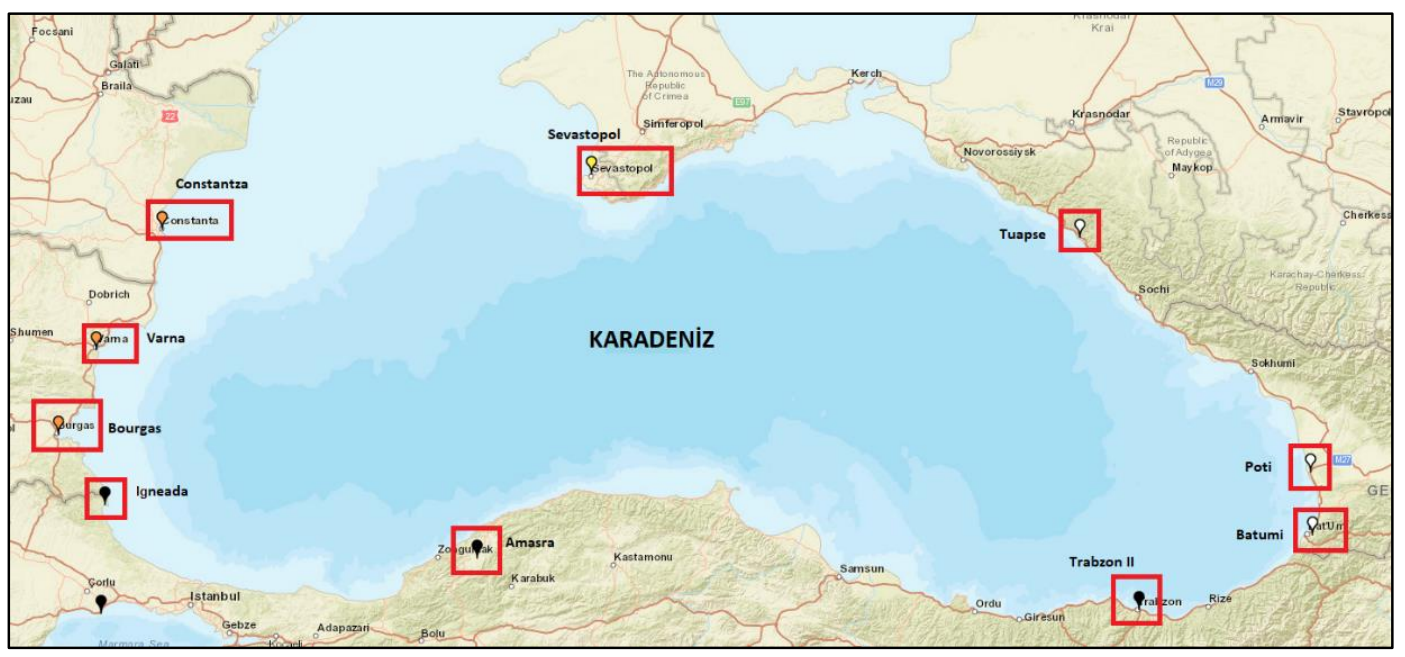

Figure.1 Tide gauge stations used in this study (https://www.psmsl.org/data/obtaining/map.html) 
Table 1 Tide gauge stations and geographic coordinates

\begin{tabular}{llclc}
\hline Station & Country & $\begin{array}{l}\text { Latitude } \\
(\text { Degree })\end{array}$ & $\begin{array}{l}\text { Longitude } \\
(\text { Degree) }\end{array}$ & Time Span \\
\hline Amasra & Turkey & 41.4333 & 32.2333 & $2001-2009$ \\
Batumi & Georgia & 41.6333 & 41.7000 & $1882-2015$ \\
Bourgas & Bulgaria & 42.4833 & 27.4833 & $1929-1996$ \\
Constantza & Romania & 44.1666 & 28.6666 & $1933-1997$ \\
Igneada & Turkey & 41.8833 & 28.0166 & $2002-2009$ \\
Poti & Georgia & 42.1666 & 41.6833 & $1874-2015$ \\
Sevastapol & Ukraine & 44.6166 & 33.5333 & $1910-1994$ \\
Trabzon II & Turkey & 41.0000 & 39.7333 & $2002-2009$ \\
Tuapse & Russia & 44.1000 & 39.0666 & $1917-2017$ \\
Varna & Bulgaria & 43.1833 & 27.9166 & $1929-1996$ \\
\hline
\end{tabular}

\subsection{Singular Spectrum Analysis}

Singular spectrum analysis is a powerful filtration technique. This method has a wide range of applications in the fields of hydrology, oceanography, medicine, economy and earth sciences. SSA is a nonparametric approach that is widely used in time series analysis (Hassani et al. 2009). This method extracts periodic and quasi-periodic signals in a time series. A spectrum of eigenvalues is used to determine these signals.

The SSA technique consists of four steps: embedding, singular value decomposition, grouping and diagonal averaging. In the first stage, the original time series is decomposed, and in the second stage, the original time series is reconstructed. Embedding and singular value decomposition belong to the decomposition stage, and the grouping and diagonal averaging belong to the reconstruction stage. The steps of this technique are shown in Figure 2. The main components selected for reconstruction include information about the trend and harmonic component. Spectral decomposition and reconstruction provide a susceptible determination of trends, seasonal fluctuations, and low frequency components.

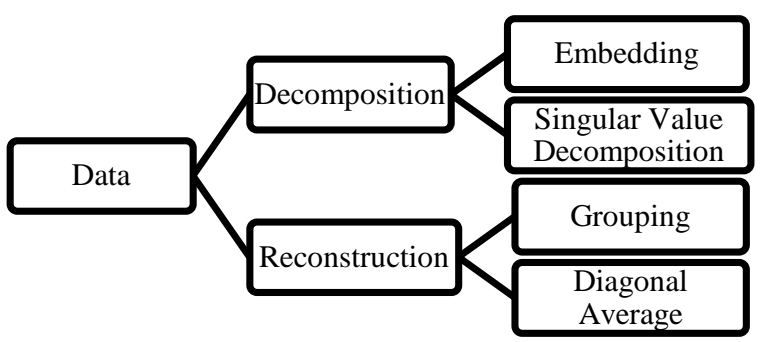

Figure. 2 Singular spectrum analysis steps

The first step in the SSA technique is embedding. In this step, a one-dimensional series is transferred into a multidimensional series. Therefore, the Hankel matrix (trajectory matrix) is taken from the original time series.
Time series $\mathbf{X}=\left(\mathbf{x}_{1}, \ldots, \mathbf{x}_{\mathrm{N}}\right)$, with length $\mathrm{N}$, is equalized to an L-series vector, as shown in Eq.(1).

$\mathbf{X}_{\mathbf{i}}=\left(\mathbf{x}_{\mathbf{i}}, \ldots, \mathbf{x}_{\mathbf{i}+\mathbf{L}-\mathbf{1}}\right)^{\mathbf{T}}$

where $\mathrm{L}$ is the window length, or embedding dimension; $\mathbf{1}<\mathbf{L}<\mathbf{N}$; and $\mathbf{1} \leq \mathbf{i} \leq \mathbf{K}$, where

$\mathbf{K}=\mathbf{N}-\mathbf{L}+\mathbf{1}$

The Hankel matrix of series X,

$\mathbf{X}=\left[\mathbf{X}_{1}, \ldots, \mathbf{X}_{\mathbf{N}}\right]=\left(\mathbf{x}_{\mathbf{i j}}\right)_{\mathbf{i}, \mathbf{j}=\mathbf{1}}^{\mathbf{L}, \mathbf{K}}=\left[\begin{array}{ccc}\mathbf{x}_{1} & \ldots & \mathbf{x}_{\mathbf{K}} \\ \mathbf{x}_{2} & \ldots & \mathbf{x}_{\mathbf{K}+1} \\ \vdots & \ldots & \vdots \\ \mathbf{x}_{\mathbf{L}} & \ldots & \mathbf{x}_{\mathbf{N}}\end{array}\right]$

The second step in SSA is the singular value decomposition (SVD). Then, the computed eigenvalues and eigenvectors of the matrix $\mathbf{S}=\mathbf{X X}^{\mathbf{T}}$ and SVD are applied to the Hankel matrix X.

$\mathbf{X}=\sum_{\mathbf{i}=\mathbf{1}}^{\mathbf{d}} \sqrt{\boldsymbol{\lambda}_{\mathbf{i}}} \mathbf{U}_{\mathbf{i}} \mathbf{V}_{\mathbf{i}}^{\mathbf{T}}$

where $\boldsymbol{\lambda}_{\mathbf{i}}$, is the eigenvalue of the $\mathrm{S}$ matrix $\left(\boldsymbol{\lambda}_{\mathbf{1}} \geq \boldsymbol{\lambda}_{\mathbf{2}} \ldots \geq\right.$ $\left.\lambda_{\mathbf{L}} \geq \mathbf{0}\right)$. According to SSA theory, close eigenvalues indicate the existence of seasonal components in the time series (Khelifa vd.,2016). In Eq. 4 , the $\left(\sqrt{\boldsymbol{\lambda}_{\mathbf{i}}}, \mathbf{U}_{\mathbf{i}}, \mathbf{V}_{\mathbf{i}}\right)$ components are referred to as the eigentriple of the $\mathrm{X}$ matrix, where $\mathbf{U}_{\mathbf{i}}$ is the normalised eigenvector corresponding to the eigenvalues.

When the eigenvalues are found, the decomposition stage is completed and proceeds to the reconstruction stage. The grouping step is first applied in this stage. The $\mathrm{X}$ matrix is split into several groups, and the matrices in each group are summed. Let,

$\mathbf{X}_{\mathbf{i}}=\sqrt{\boldsymbol{\lambda}_{\mathbf{i}}} \mathbf{U}_{\mathbf{i}} \mathbf{V}_{\mathbf{i}}^{\mathbf{T}}$

$\mathbf{X}_{\mathbf{I}}=\mathbf{X}_{\mathbf{i}_{1}}+\mathbf{X}_{\mathbf{i}_{2}}+\cdots+\mathbf{X}_{\mathbf{i}_{\mathrm{m}}}, \quad \mathbf{I}=\left\{\mathbf{i}_{1}, \ldots, \mathbf{i}_{\mathbf{m}}\right\}$

Here, $\mathbf{I}=\left\{\mathbf{i}_{\mathbf{1}}, \ldots, \mathbf{i}_{\mathbf{m}}\right\}$ represents eigentriple grouping. Then, each matrix $\mathbf{X}_{\mathbf{I j}}(\mathbf{j}=\mathbf{1}, \ldots, \mathbf{d})$ is transformed into a new series with length $\mathrm{N}$, where $\mathrm{d}$ is the rank of a matrix. This step is referred to as diagonal averaging. 
Let the $\mathrm{Y}$ matrix be computed. $\mathrm{Y}$ is the length $\mathbf{L} \times \mathbf{K}$ matrix, and $\mathbf{y}_{\mathbf{i j}}$ is an element of $\mathbf{Y}\left(\mathbf{y}_{1}, \mathbf{y}_{2}, \ldots, \mathbf{y}_{\mathbf{N}}\right)$. As a result, $\mathrm{Y}$ is converted to series $\left(\mathbf{y}_{1}, \mathbf{y}_{2}, \ldots, \mathbf{y}_{\mathbf{N}}\right)$, and the reconstruction elements are written as:

$\mathbf{y}_{\mathbf{k}}= \begin{cases}\frac{1}{\mathbf{k}} \sum_{\mathbf{m}=1}^{\mathbf{k}} \mathbf{y}_{\mathbf{m}, \mathbf{k}-\mathbf{m}+\mathbf{1}}^{*} & 0 \leq \mathbf{k}<\mathbf{L}^{*} \\ \frac{1}{\mathbf{L}^{*}} \sum_{\mathbf{m}=1}^{\mathbf{L}^{*}} \mathbf{y}_{\mathbf{m}, \mathbf{k}-\mathbf{m}+\mathbf{1}}^{*} & \mathbf{L}^{*} \leq \mathbf{k}<\mathbf{K}^{*} \\ \frac{\mathbf{1}}{\mathbf{N}-\mathbf{k}+\mathbf{1}} \sum_{\mathbf{m}=\mathbf{k}-\mathbf{K}^{*}+\mathbf{1}}^{\mathbf{N}-\mathbf{y}_{\mathbf{m}, \mathbf{k}-\mathbf{m}+\mathbf{1}}^{*}} & \mathbf{K}^{*} \leq \mathbf{k}<\mathbf{N}\end{cases}$

where $\quad \mathbf{1} \leq \mathbf{i}<\mathbf{L} \quad, \quad \mathbf{1} \leq \mathbf{j} \leq \mathbf{K}, \mathbf{i}+\mathbf{j}=\mathbf{k}+\mathbf{1}, \mathbf{L}^{*}=$ $\min (\mathbf{L}, \mathbf{K})$ and $\mathbf{K}^{*}=\max (\mathbf{L}, \mathbf{K})$. If $\mathbf{L}<\mathbf{K}, \mathbf{y}_{\mathbf{i j}}^{*}=\mathbf{y}_{\mathbf{i j}}$ and $\mathbf{y}_{\mathrm{ij}}^{*}=\mathbf{y}_{\mathrm{ji}}$; otherwise, the choice $\mathbf{k}=\mathbf{1}$ gives $\mathbf{y}_{\mathbf{1}}=\mathbf{y}_{\mathbf{1}, \mathbf{1}}$, and for $\mathbf{k}=\mathbf{2}, \mathbf{y}_{\mathbf{2}}=\left(\mathbf{y}_{1,2}+\mathbf{y}_{2,1}\right) / \mathbf{2}$ (Moreno and Coelho 2018; Osmanzade 2017; Hassani and Thomakos 2010; Golyandina et al., 2001).

\section{APPLICATION}

In this paper, we aim to determine sea level change along the coasts of the Black Sea using SSA. With the SSA, the trend and seasonal effect on the mean sea level can be determined. The mean sea level time series recorded at the tide gauge stations used in this study are presented in Figure 3. At the 10 tide gauge locations along the coasts of the Black Sea, mean sea level data in the period 1930-2017 showed similar changes.

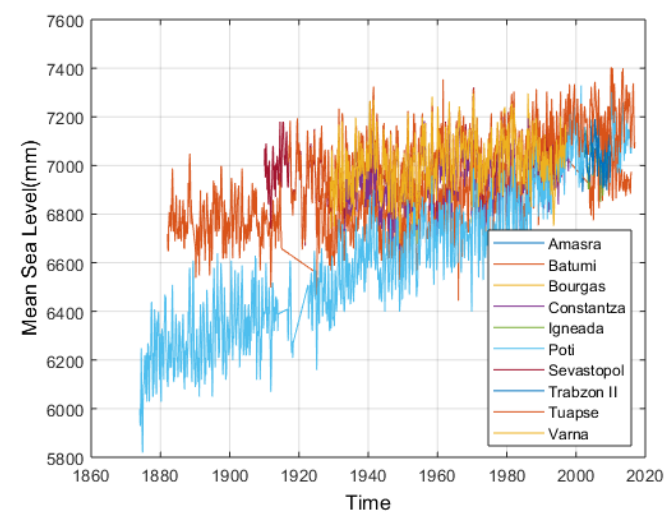

Figure. 3 Tide gauge station time series graphics

The window length (L) is determined for the decomposition stage of the SSA. Determining the window or embedding dimension (L) is one of the most critical steps of this method. The main components decompose better when the $\mathrm{L}$ value is large (Hassani et al., 2009). However, there is no strict rule for determining window length. Hassani et al. (2009) suggested that $\mathrm{L}$ is selected as the median of the $1,2, \ldots, N$ values. Golyandina (2010) proposed that $\mathrm{L} \leq \mathrm{N} / 2$ be selected. In this study, the window length $\mathrm{L}$ for each station was selected as $\mathrm{N} /$ 2. Thus, we computed the $\mathrm{L} \times \mathrm{L}$ Hankel matrix and $\mathrm{L}$ eigentriples.

According to the eigenvalues, we observed that there are close eigenvalue groups. The close eigenvalues of the stations are identified as harmonic components. At the same time, the eigenvalues are close to each other, showing the presence of a seasonal component in the time series. There are close eigenvalues at the Batumi,
Constantza, Poti, Sevastapol, Trabzon II, Tuapse and Varna stations, as presented in Figure 4. The first harmonic eigenvectors are shown in Table 2.

Table 2 Harmonic eigenvectors

\begin{tabular}{cc}
\hline Station Name & Harmonic eigenvectors \\
\hline Batumi & $6-7$ \\
Constantza & $5-6,15-16,17-18,21-22$ \\
Poti & $3-4$ \\
Sevastapol & $1-2,7-8,9-10$ \\
Trabzon II & $7-8,10-11$ \\
Tuapse & $5-6$ \\
Varna & $21-22,24-25,28-29$ \\
\hline
\end{tabular}
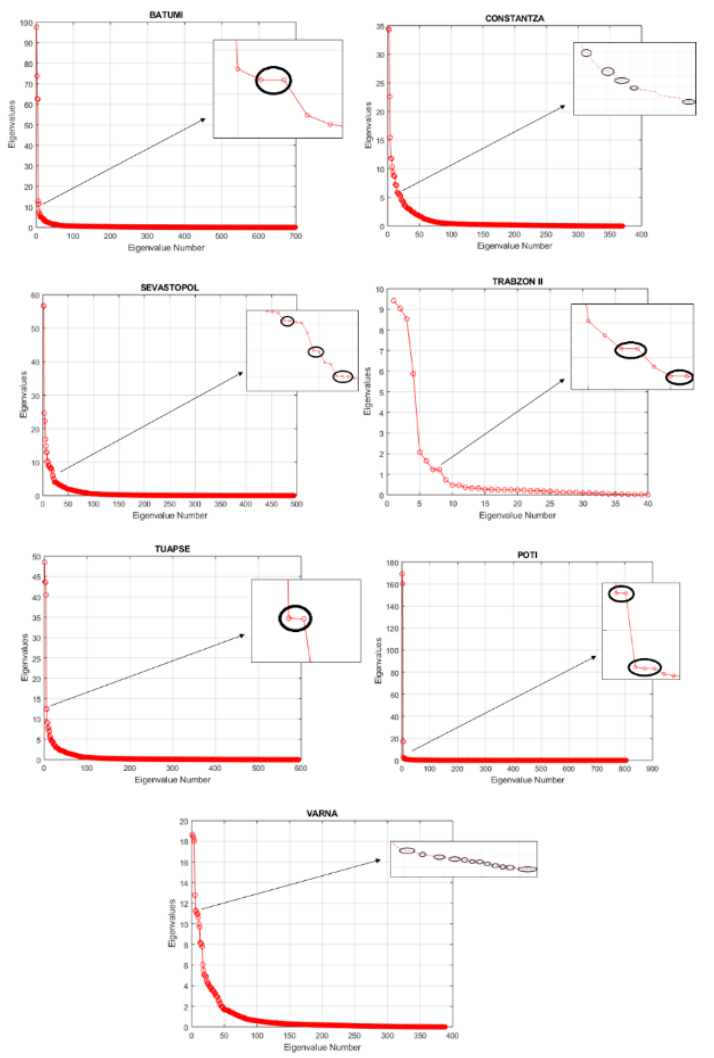

Figure. 4 Eigenvalues of Batumi, Constantza, Poti, Sevastapol, Trabzon II, Tuapse and Varna stations.

Then, the reconstruction stage is achieved using Eq. (5), Eq. (6) and Eq. (7). The difference trend solutions are computed as a result of different combinations of eigentriples. For this, the eigentriples must be selected, as they are the best representation of the data. In this study, the first five reconstruction components (RCs) were selected for each station. Because, according to the RCs graphics, the first five RCs contain practically all trend and seasonal components of time series. RCs are shown in the time series graphics (Figure 5). The RCs that best represented the trend were found in the time series for each station. 

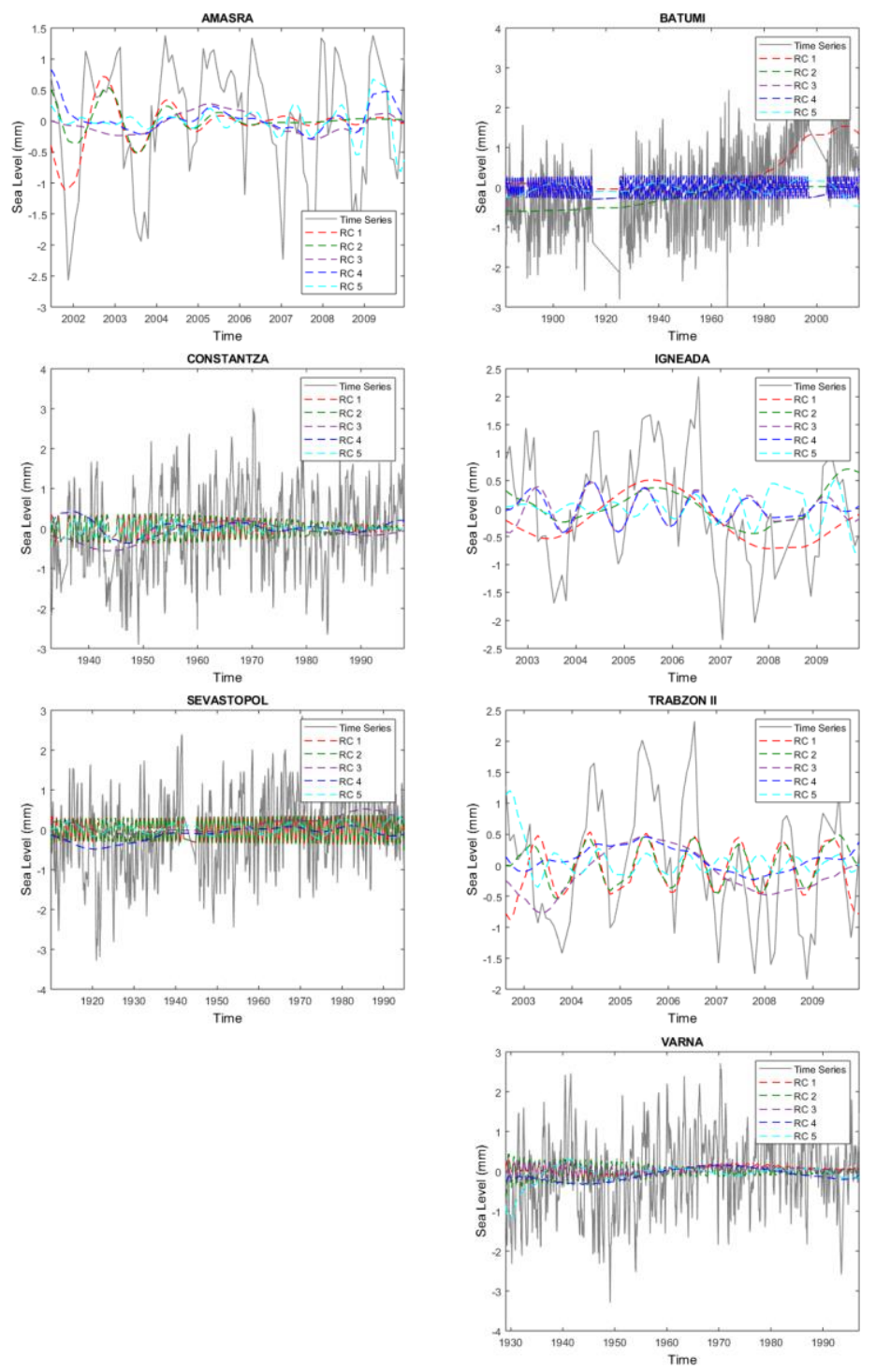
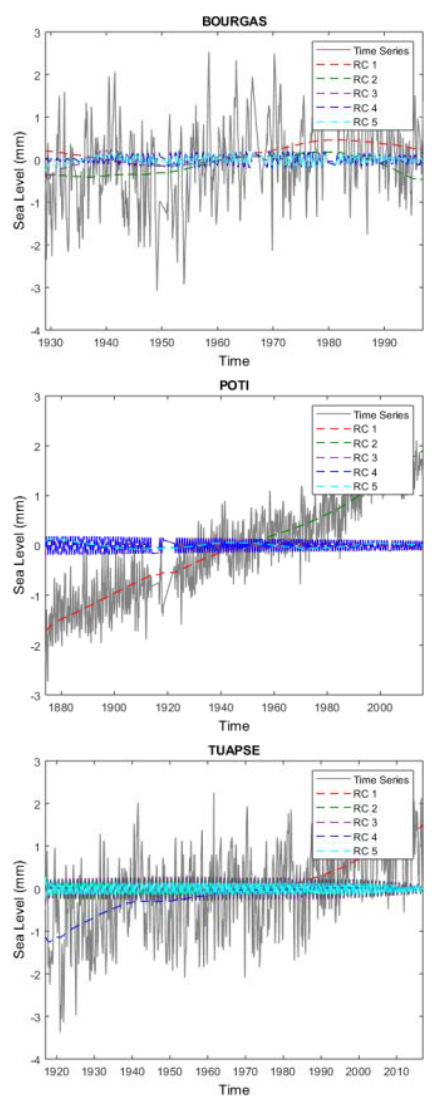

Figure. 5 Reconstruction components of the tide gauges

The slowly varying eigenvalues present the trend (Hassani, 2007).

It is realized that the sum of the reconstructed components present initial time series. The sum of the reconstruction components that best represent the trend for each station is shown on the time series graphics (Figure 6, Figure 7 and Figure 9).
At the Batumi, Poti and Tuapse stations, most data records have increasing trends in the mean sea level. The trends show that the mean sea level at Batumi station increased from $-0.11 \mathrm{~mm}$ to $0.85 \mathrm{~mm}$ during the period of 1882-2015, that at the Poti station increased from -1.62 $\mathrm{mm}$ to $1.82 \mathrm{~mm}$ during the period of $1874-2015$, and that at the Tuapse station increased from $-1.09 \mathrm{~mm}$ to $1.39 \mathrm{~mm}$ during the period of 1917-2017. The results are presented in Figure 6. 

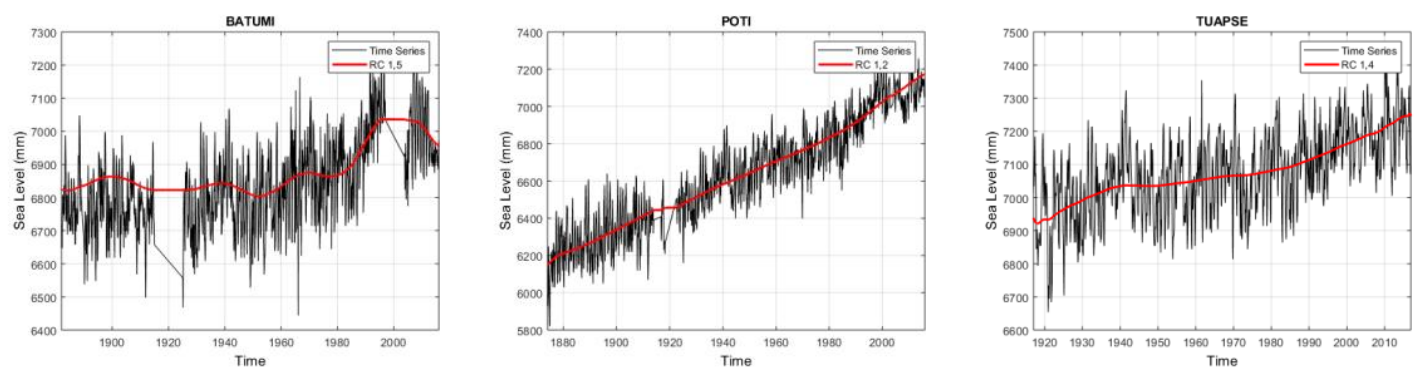

Figure. 6 Batumi, Poti and Tuapse station time series and reconstruction components

The mean sea level at the Bourgas station has no significant change from $-0.13 \mathrm{~mm}$ to $-0.21 \mathrm{~mm}$ during the period of 1929-1996. That at the Constantza station increased from $-0.06 \mathrm{~mm}$ to $0.14 \mathrm{~mm}$ during the period of 1933-1997, and that at the Sevastopol station increased from $0.002 \mathrm{~mm}$ to $0.17 \mathrm{~mm}$ during the period
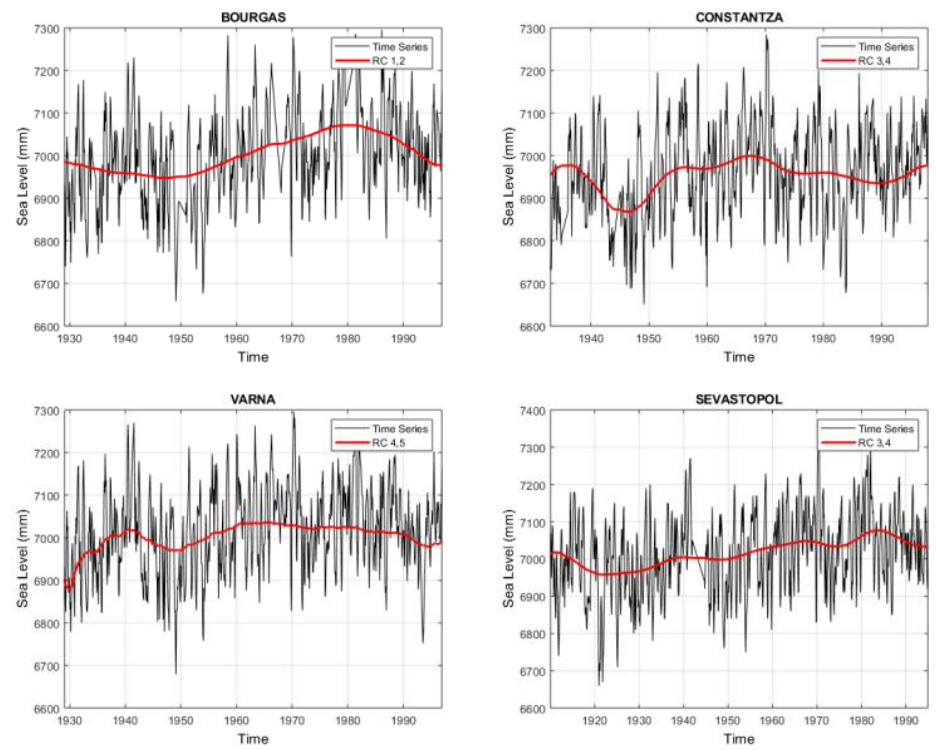

of 1910-1994. The mean sea level at the Varna station changed from $-1.10 \mathrm{~mm}$ to $-0.16 \mathrm{~mm}$ during the period of 1929-1996. The results are presented in Figure 7. The increasing trend stations are shown in Figure 8.

Figure. 7 Bourgas, Constantza, Sevastopol and Varna station time series and reconstruction components 


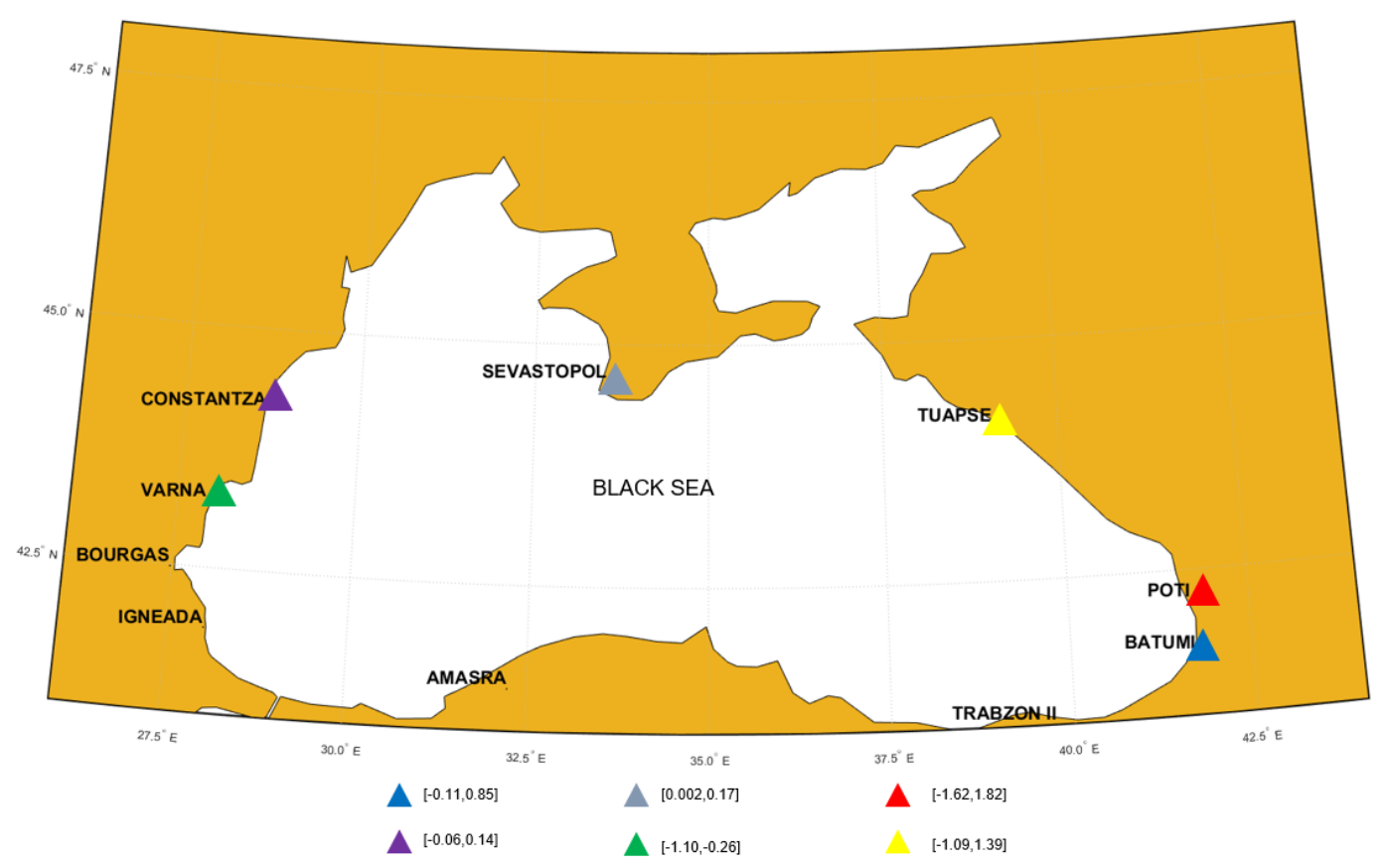

Figure. 8 Increasing trend stations in the Black Sea coasts ( $\Delta$ denotes increasing trends)

The Amasra, Igneada and Trabzon II tide gauge stations have inadequate data records. These stations have short time series. Thus, the mean sea level change could not be clearly determined. The mean sea level at the Amasra station changed from $0.44 \mathrm{~mm}$ to $0.02 \mathrm{~mm}$ during the period of 2001-2009, that at the Igneada station changed from $0.11 \mathrm{~mm}$ to $0.54 \mathrm{~mm}$ during the period of 20022009, and that at the Trabzon-II station changed from $0.10 \mathrm{~mm}$ to $0.37 \mathrm{~mm}$ during the period of 2002-2009 (Figure 9).
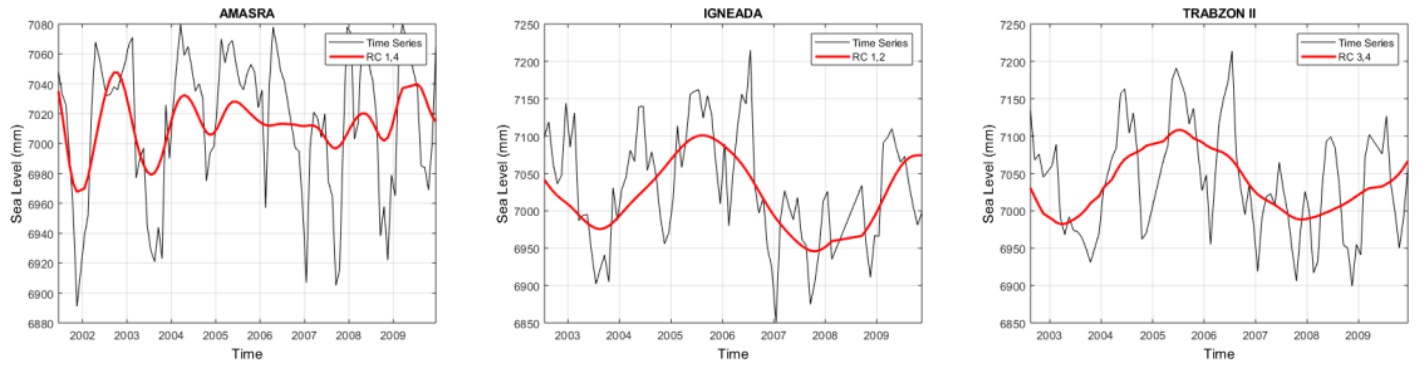

Figure. 9 Amasra, Igneada and Trabzon II station time series and reconstruction components 


\section{CONCLUSION}

In this study, we used the SSA method to detect mean sea level change at 10 tide gauge stations along the coasts of the Black Sea. In addition, we detected the seasonal influence in the time series. To this end, we discuss the results of the analysis.

In the analysis results, there are increasing trends at the Batumi (Georgia), Poti (Georgia), Tuapse (Russia),
Constantza (Romania), Sevastapol (Ukraine) and Varna (Bulgaria) stations.

The Amasra, Igneada and Trabzon II tide gauge stations in Turkey were inadequate in interpreting this change. The analysis results are shown in Table 3.

Table 3 Trends at the tide gauge stations

\begin{tabular}{lllll}
\hline Station & $\begin{array}{l}\text { Trend } \\
(\mathrm{mm})\end{array}$ & Mean & $\begin{array}{l}\text { Mean Square } \\
\text { Error } \\
(\mathrm{mm})\end{array}$ & $\begin{array}{l}\text { Data Record } \\
\text { Span } \\
\text { (year) }\end{array}$ \\
\hline Batumi & {$[-0.11,0.85]$} & 0.26 & 0.50 & 133 \\
Constantza & {$[-0.06,0.14]$} & -0.08 & 0.30 & 64 \\
Sevastopol & {$[0.02,0.17]$} & 0.02 & 0.31 & 64 \\
Varna & {$[-1.10,-0.26]$} & -0.14 & 0.28 & 67 \\
Poti & {$[-1.62,1.82]$} & 0.005 & 0.93 & 141 \\
Tuapse & {$[-1.09,1.39]$} & 0.004 & 0.62 & 100 \\
Igneada & {$[0.11,0.54]$} & -0.12 & 0.60 & 7 \\
Amasra & {$[0.44,0.02]$} & -0.02 & 0.35 & 8 \\
Trabzon II & {$[-0.10,0.37]$} & -0.04 & 0.51 & 7 \\
Bourgas & {$[-0.13,-0.21]$} & 0.002 & 0.37 & 67 \\
\hline
\end{tabular}

The results showed that for the Batumi (Georgia) station, the station values of the trend in the 133-year period are from $-0.11 \mathrm{~mm}$ to $0.85 \mathrm{~mm}$, and for the Poti (Georgia) station, the station values of the trend in the 141-year period are from $-1.62 \mathrm{~mm}$ to $1.82 \mathrm{~mm}$. For the Bourgas (Bulgaria) and Varna (Bulgaria) stations, the trend values for the same period are from $-0.13 \mathrm{~mm}$ to 0.21 and from $-1.10 \mathrm{~mm}$ to $-0.26 \mathrm{~mm}$, respectively.

If the eigenvalues are close to each other, this situation showing the presence of a seasonal component in the time series. According to the eigenvalue results, the Batumi, Constantza, Sevastopol, Poti, Tuapse, Trabzon II and Varna stations have close eigenvalues. This situation indicates the presence of a seasonal component in the time series of related stations. No seasonal components found at the other stations (Amasra, Igneada and Bourgas).

\section{ACKNOWLEDGEMENTS}

The authors are grateful to Permanent Service for Mean Sea Level (PSMSL) for providing the mean sea level data.

\section{REFERENCES}

Avşar N.B., Kutoglu S.H., Erol B., Jin S.G. (2015). Sea level changes in the Black Sea using satellite altimetry and tide-gauge observations. Proceedings of the 26th IUGG General Assembly, Prag, Czech Republic.

Cazenave A., Dieng H.B., Meyssignac B., von Schuckmann K., Decharme B. (2014). The rate of sealevel rise. Nature Climate Change, 4(5), pp.358-361.

Ghil M., Allen R. M., Dettinger M.D., Ide K., Kondrashov D., Mann M.E., Robertson A.W., Saunders A., Tian Y., Varadi F. and Yiou P. (2002). Advanced spectral methods for climatic time series. Reviews of Geophysics, 40, pp. 1-41.

Golyandina N. (2010). On the choice of parameters in singular spectrum analysis and related subspace-based methods. Statistics and Its Interface, 3,pp. 259-279.

Golyandina N., Nekrutkin V., Zhigljavsky A. (2001). Analysis of time series structure: SSA and related techniques. Chapman \& Hall/CRC, Boca Raton.

Golyandina N., Zhigljavsky, A. (2013). Singular spectrum analysis for time series. Springer, doi: 10.1007/978-3-642-34913-3.

Goriacikin I.N., Ivanov V.A. (2006). Black Sea Level: Past, Present, Future, (in Russian). EKOCI-Gidrofizica, Sevastopol,210.

Hassani H. (2007). Singular spectrum analysis: methodology and comparison. Journal of Data Science, 5(2), pp.239-257.

Hassani H., Heravi S., Zhigljavsky A. (2009). Forecasting European industrial production with singular spectrum analysis. International Journal of Forecasting, 25(1),pp. 103-118.

Hassani H., Thomakos D. (2010). A review on singular spectrum analysis for economic and financial time series. Statistics and Its Interface, 3, pp. 377-397.

Karaca M., Ünal Y.S. (2003). Potential 1mplications of accelerated sea-level rise for Turkey. Journal Coastal Research, 24, pp. 288-298. 
Khelifa S., Gourine B., Rami A., Taibi H. (2016). Assessment of nonlinear trends and seasonal variations in global sea level using singular spectrum analysis and wavelet multiresolution analysis. Arabian Journal of Geosciences, 9:560, doi: 10.1007/s12517-016-2584-6.

Kubryakov A.A., Stanichny S. (2013). The Black Sea level trends from tide gages and satellite altimetry. Russian Meteorology and Hydrology, 38(5), doi: 10.3103/S1068373913050051.

Moreno S.R., Coelho L.D.S. (2018). Wind speed forecasting approach based on singular spectrum analysis and adaptive neuro fuzzy inference system. Renewable Energy, 126, pp. 736-754.

Nacef L., Bachari N.E.I., Bouda A. and Boubnia R. (2016). Variability and decadal evolution of temperature and salinity in the Mediterranean sea surface. International Journal of Engineering and Geosciences, 1, pp. 24-33.
Osmanzade A. (2017). Singular spectrum analysis forecasting for financial time series. Master Thesis, University of Tartu, Tartu.

Yilmaz M., Turgut B., Gullu M., Yilmaz I. (2016). Evaluation of recent global geopotential models by GNSS/Levelling data: internal Aegean region. International Journal of Engineering and Geosciences, 1, pp.18-223.

URL-1

https://tudes.harita.gov.tr/tudesportal/Hakkında.aspc.

URL 2- https://www.psmsl.org/data/

Vigo I., Garcia D., Chao B.F. (2005). Change of sea level trend in the Mediterranean and Black seas. Journal of Marine Research, 63, pp. 1085-1100. 